\title{
Effects of Shear Lag in Steel Box Girders of a Crane Runway
}

\author{
Cătălin Moga, Delia Drăgan, Raluca Nerișanu
}

\begin{abstract}
The term of shear lag is related to the discrepancies between the approximate theory of the bending of beams and their real behaviour. It refers to the increases of the bending stresses near the flange-to-web junctions and the corresponding decreases in the flange stresses away from these junctions. In the case of wide flanges of plated structures, shear lag caused by shear strains, which are neglected in the conventional theory, may be taken into account by a reduced flange width concentrated along the webs of the steel girders. In EN 1993-1-5, the concept of taking shear lag into account is based on effective width of the flange which is defined in order to have the same total normal force in the gross flange subjected to the real transverse stress distribution as the effective flange subjected to a uniform stress equal to the maximum stress of the real transverse distribution. Some aspects concerning the shear lag phenomenon and a working example for a box girder of a heavy crane runway to illustrate the determination of the shear lag effect are also presented.
\end{abstract}

Keywords - crane runway girder, interaction shear lag-plate buckling, EN 1993-1-5, EN 1993-6, shear lag

\section{INTRODUCTION}

In the conventional theory of bending, shear strains are neglected so that it can be assumed that plane sections remain plane after loading.

The term shear lag is related to some of the discrepancies between this approximate theory of the bending of beams and their real behaviour, and in particular, refers to the increases of the bending stresses near the flange-to-web junctions, and the corresponding decreases in the flange stresses away from these junctions [4]. In the case of wide flanges of plated structures, shear lag may be taken into account by a reduced flange width concentrated along the webs for the verification of stresses, especially for short spans, since it causes the longitudinal stress at a flange/web intersection to exceed the average stress in the flange.

An approximate method of dealing with shear lag is to use the effective width concept, in which the actual width $\mathrm{b}$ of a flange is replaced by a reduced width $b_{\text {eff }}$, Fig. 1 .

This approach is similar to the one used to allow the redistribution of stress which takes place in a thin compression flange after local buckling, but the two effects of shear lag and local buckling are quite distinct, and should not be confused [4]. 
In relation to the effective width method, SR EN 1993-1-5. \$3.3 introduces three different designations for three types of effective width [1], [2], [6]:

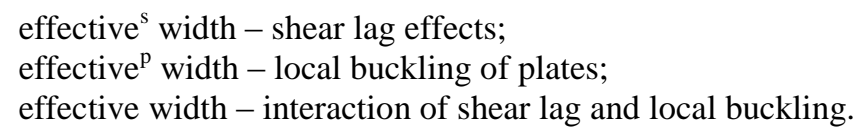

When designing plated structures, the effects of shear lag, plate buckling and interaction of both effects should be taken into account at the ultimate, serviceability or fatigue limit states.

For simplicity reasons, the effectives width may be taken as constant over the length of each span:

$b_{\text {eff }}=\min \left(b_{0} ; \frac{L_{i}}{8}\right)$
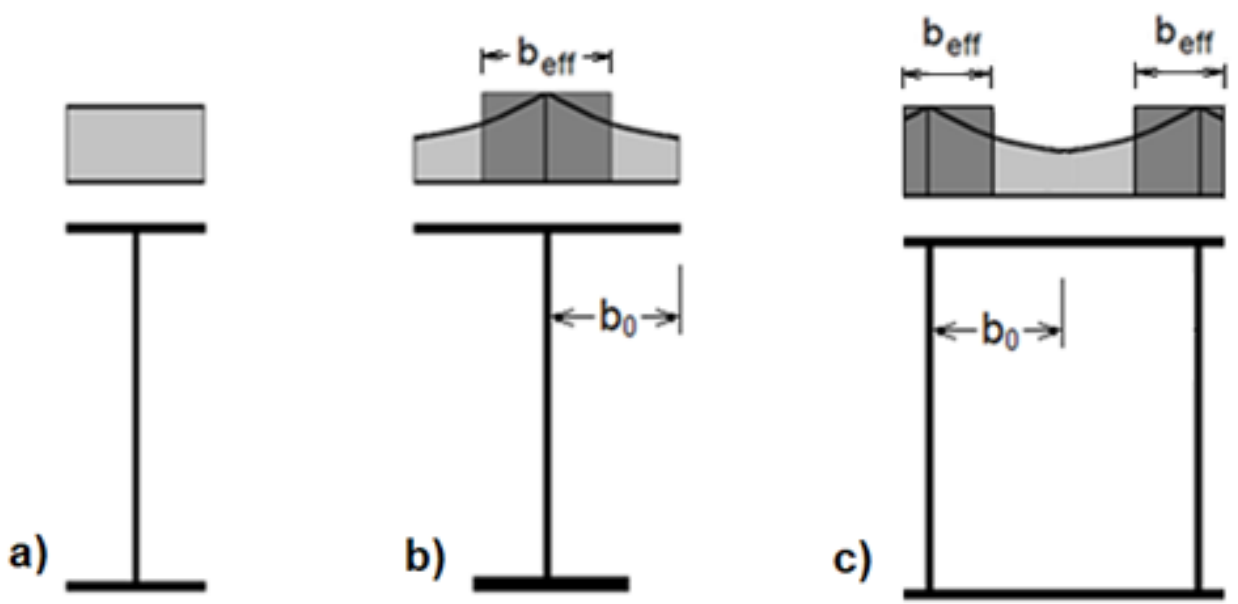

Fig. 1. Effective width due to shear lag: a) thin wide flanges;

b) wide top flange; c) box girder

\section{SHEAR LAG EVALUATION ACCORDING TO EN 1993-1-5}

\subsection{Elastic Shear Lag at Serviceability Limit State (SLS)}

In EN 1993-1-5, the concept of taking shear lag into account is based on the effective width of the flange which is defined in order to have the same total normal force in the gross flange subjected to the real transverse stress distribution as the effective flange subjected to a uniform stress equal to the maximum stress of the real transverse distribution:

$\int_{0}^{b} \sigma_{x}(y) \cdot t_{f} \cdot d y=b_{e f f} \cdot t_{f} \cdot \sigma_{x \cdot \max }$

where: $b_{e f f}=\beta \cdot b_{0} ; \beta$ is an efficiency factor given in Table 1

(extract from Table 3.1 - EN1993-1-5). 
Table. 1. Coefficient $\beta$ evaluation.

\begin{tabular}{|c|c|c|}
\hline $\begin{array}{c}\text { Location for } \\
\text { verification }\end{array}$ & $\boldsymbol{\beta}$-value & $\boldsymbol{k}$ \\
\hline $\begin{array}{c}\text { Regions of positive } \\
\text { (sagging) bending }\end{array}$ & $\beta=\beta_{1}=\frac{1}{1+6.4 \cdot k^{2}}$ & $0.02-0.70$ \\
\cline { 2 - 3 } & $\beta=\beta_{1}=\frac{1}{5.9 \cdot k}$ & $>0.70$ \\
\hline \multirow{2}{*}{$\begin{array}{c}\text { Regions of negative } \\
\text { (hogging) bending }\end{array}$} & $\beta=\beta_{2}=\frac{1}{1+6.0 \cdot\left(k-\frac{1}{2500 \cdot k}\right)+1.6 \cdot k^{2}}$ & $0.02-0.70$ \\
\cline { 2 - 3 } & $\beta=\beta_{2}=\frac{1}{8.6 \cdot k}$ & $>0.70$ \\
\hline
\end{tabular}

where: $k=\frac{\alpha_{0} \cdot b_{0}}{L_{e}}-$ factor related to the stiffening ratio $\alpha_{0}$; $\alpha_{0}=\sqrt{1+\frac{\sum A_{s \ell}}{b_{0} \cdot t_{f}}}-$ orthotropic plate factor ;

$\sum A_{s t}$ - area of all longitudinal stiffeners of $b_{0}$ width;

$L_{e}-$ effective length (Fig. 3.1 - EN 1993-1-5).

The transverse bending stresses distribution due to shear lag is given in Fig. 2 and can be evaluated with the relation given in EN1993-1-5.
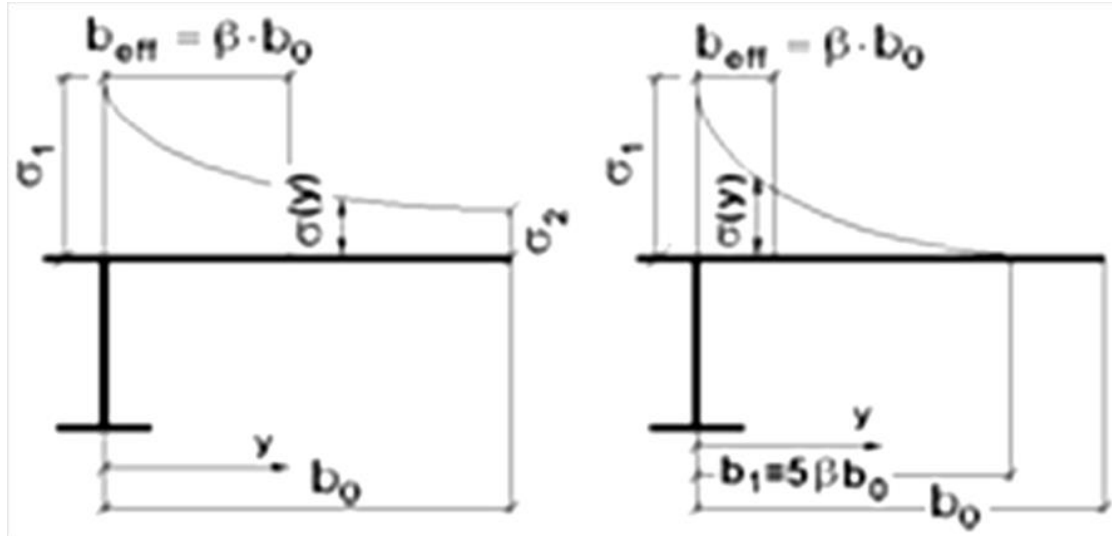

Fig. 2. Distribution of stresses due to shear lag

According to EN 1993-1-5, the shear lag in the flanges may be neglected if $b_{0}<L_{e} / 50$.

\subsection{Shear lag at ultimate limit state (ULS)}

In case of a flange in compression at ULS (ultimate limit state) verification, the plate buckling effects which results in an effective ${ }^{\mathrm{p}}$ area of the flange may occur in addition to the shear lag effects. 
At the ultimate limit state shear lag effects may be determined as follows [6]:

a) elastic shear lag effects as determined for serviceability and fatigue limit states (presented before at point 2.1);

b) combined effects of shear lag and of plate buckling;

c) elastic-plastic shear lag effects allowing for limited plastic strains.

EN 1993-1-5 proposes two models of steps for interaction between shear lag and plate buckling [1], [2], [6]:

Method b (effect of shear lag and of plate buckling) consists in:

- calculate the effective ${ }^{\mathrm{p}}$ area to plate buckling;

- define an effective ${ }^{\mathrm{p}}$ stiffening ratio $\alpha_{0}^{*}$ to be used instead of the stiffened ratio $\alpha_{0}$ and calculating the reduction factor $\beta_{u l t}$ (using Table 1) instead of $\beta$, where:

$$
\alpha_{0}^{*}=\sqrt{\frac{A_{c . e f f}}{b_{0} t}}
$$

Calculate the effective area $A_{\text {eff }}$ for taking shear lag and plate buckling effects into account as follows:

$A_{\text {eff }}=\beta_{\text {ult }} \cdot A_{c . e f f}$

Method c (elastic-plastic shear lag effects - recommended in EN 1993-1-5):

- an elastoplastic reduction factor $\beta^{k} \geq \beta$ is directly applied to the effective ${ }^{\mathrm{p}}$ area of the compression flange, where $\mathrm{k}$ is based on $\alpha_{0}$ :

$A_{\text {eff }}=\beta^{k} \cdot A_{c . e f f} \geq A_{c . e f f} \cdot \beta$

It is recommended to apply the reduction factor of the area to the thickness of the plate, and not to the width [1], [2], especially for unstiffened flange.

\section{DESIGN EXAMPLE}

A box girder for a heavy crane runway, Fig. 3, is analyzed to illustrate the determination of the shear lag effect.

The static system spans (3x $6000 \mathrm{~mm})$ and the effective lengths are presented in Fig. 4. The steel grade used in the structure is $\mathrm{S} 355$.
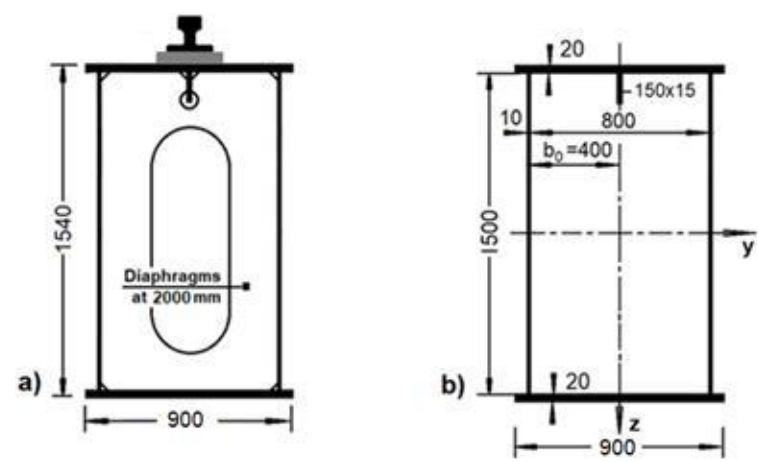

Fig. 3. Girder of a crane runway: a) general cross-section b) cross-section dimensions 
STATIC SISTEM AND EFFECTIVE LENGTHS

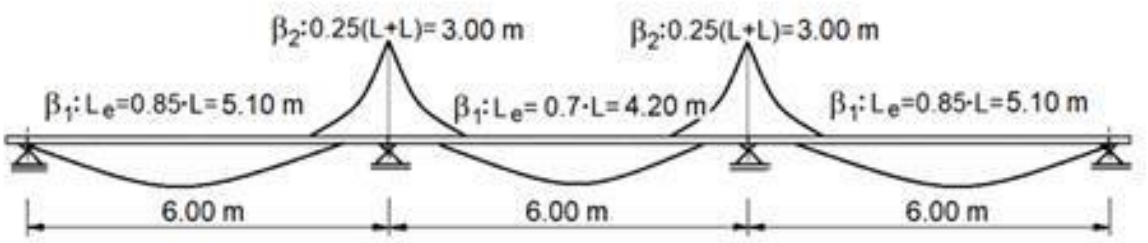

Fig. 4. Static system and effective length

\section{Elastic shear lag at serviceability limit state}

Shear lag in the flanges has to be considered in all cross-sections design because we have:

$b_{0}=400 \mathrm{~mm}>\frac{L_{e \cdot \max }}{50}=\frac{5100}{50}=102 \mathrm{~mm}$.

Elastic shear lag at serviceability and fatigue limit state is considered by using an effective ${ }^{\mathrm{s}}$ width and an elastic stress distribution.

The orthotropic plate factors are:

- for the top flange:

$\alpha_{0}=\sqrt{1+\frac{\sum A_{s \ell}}{b_{0} \cdot t_{f}}}=\sqrt{1+\frac{0.5 \cdot 1.5 \cdot 15}{40 \cdot 2.0}}=1.068$

- for the lower flange:

$\alpha_{0}=\sqrt{1+\frac{\sum A_{s \ell}}{b_{0} \cdot t_{f}}}=\sqrt{1+\frac{0.0}{40 \cdot 2.0}}=1.0$

\section{Marginal spans}

Top flange: $k=\frac{\alpha_{0} \cdot b_{0}}{L_{e}}=\frac{1.068 \cdot 400}{5100}=0.084 ; \beta_{1}=\frac{1}{1+6.4 \cdot k^{2}}=\frac{1}{1+6.4 \cdot 0.084^{2}}=0.957$;

$b_{\text {eff }}=\beta_{1} \cdot b_{0}=0.957 \cdot 400=383 \mathrm{~mm}$.

Lower flange: $k=\frac{\alpha_{0} \cdot b_{0}}{L_{e}}=\frac{1.0 \cdot 400}{5100}=0.078 ; \beta_{1}=\frac{1}{1+6.4 \cdot \mathrm{k}^{2}}=\frac{1}{1+6.4 \cdot 0.078^{2}}=0.963$;

$b_{e f f}=\beta_{1} \cdot b_{0}=0.963 \cdot 400=385 \mathrm{~mm}$.

Internal span

Top flange: $k=\frac{\alpha_{0} \cdot b_{0}}{L_{e}}=\frac{1.068 \cdot 400}{4200}=0.102 ; \beta_{1}=\frac{1}{1+6.4 \cdot k^{2}}=\frac{1}{1+6.4 \cdot 0.102^{2}}=0.937$;

$b_{\text {eff }}=\beta_{1} \cdot b_{0}=0.937 \cdot 400=375 \mathrm{~mm}$. 
Sciendo $_{28}$ Ovidius University Annals Series: Civil Engineering, Year 22, 2020

Lower flange: $k=\frac{\alpha_{0} \cdot b_{0}}{L_{e}}=\frac{1.0 \cdot 400}{4200}=0.095 ; \beta_{1}=\frac{1}{1+6.4 \cdot \mathrm{k}^{2}}=\frac{1}{1+6.4 \cdot 0.095^{2}}=0.945$;

$b_{\text {eff }}=\beta_{1} \cdot b_{0}=0.945 \cdot 400=378 \mathrm{~mm}$.

\section{Internal support}

Top flange: $k=\frac{\alpha_{0} \cdot b_{0}}{L_{e}}=\frac{1.068 \cdot 400}{3000}=0.142 ; \beta_{2}=\frac{1}{1+6.0 \cdot\left(k-\frac{1}{2500 \cdot k}\right)+1.6 \cdot k^{2}}=0.535$;

$b_{\text {eff }}=\beta_{2} \cdot b_{0}=0.535 \cdot 400=214 \mathrm{~mm}$.

Lower flange: $k=\frac{\alpha_{0} \cdot b_{0}}{L_{e}}=\frac{1.0 \cdot 400}{3000}=0.133 ; \beta_{2}=\frac{1}{1+6.0 \cdot\left(k-\frac{1}{2500 \cdot k}\right)+1.6 \cdot k^{2}}=0.553$;

$b_{\text {eff }}=\beta_{2} \cdot b_{0}=0.553 \cdot 400=221 \mathrm{~mm}$.

The effective and non-effective zones related to effective ${ }^{\mathrm{s}}$ widths for shear lag under elastic conditions are graphically presented in Fig. 5, where: $b_{\text {non-eff }}=800 \mathrm{~mm}-2 \cdot b_{\text {eff }}$.
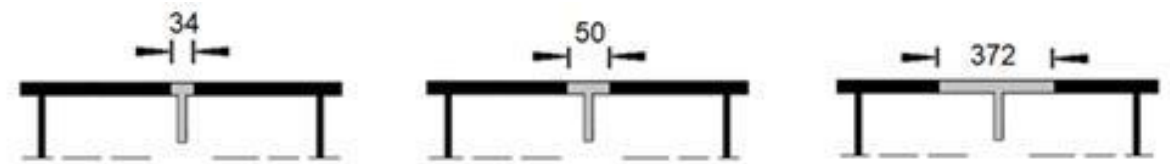

a)

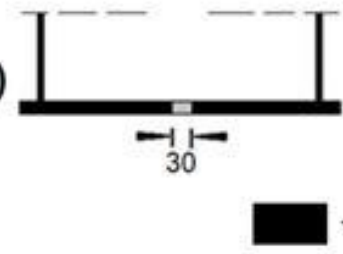

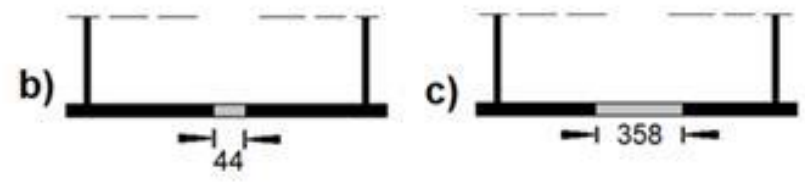

- effective zone

- non-effective zone

Fig. 5. Effective and non-effective zones of flanges: a) marginal spans; b) internal span; c) internal support

Shear lag at ultimate limit state at intermediate support

At the ULS shear lag effects may be conservatively determined as elastic shear lag or elastoplastic shear lag effects with limited plastic strains. When plate buckling is also present, the combined effect of shear lag and plate buckling should be considered.

Combined effects of shear lag and of plate buckling

In the tensioned upper flange, there is no interaction with plate buckling and only shear lag is present $-b_{\text {eff }}=\beta_{2} \cdot b_{0}=0.535 \cdot 400=214 \mathrm{~mm} \quad$ and $b_{\text {non-eff }}=800 \mathrm{~mm}-2 \cdot b_{\text {eff }}=372 \mathrm{~mm}$.

Lower flange class section: $\frac{c}{t}=\frac{800}{20}=40>42 \varepsilon=34 \Rightarrow 4^{\text {th }}$ class; 


$$
\overline{\lambda_{p}}=\frac{b_{p} / t}{28.4 \varepsilon \cdot \sqrt{k_{\sigma}}}=\frac{40}{28.4 \cdot 0.81 \cdot \sqrt{4}}=0.87>0.673 ; \rho=\frac{\overline{\lambda_{p}^{-}-0.055(3+\Psi)}}{\lambda_{p}^{-2}}=\frac{0.87-0.055 \cdot 4}{0.87^{2}}=0.86 .
$$

The effective ${ }^{\mathrm{p}}$ width for the all lower flange will be $b_{e f f}^{p}=0.86 \cdot b=0.86 \cdot 800=688 \mathrm{~mm}$, and at both sides of the web $b_{1 . e f f}^{p}=688 / 2=344 \mathrm{~mm}$.

The effective ${ }^{\mathrm{s}}$ width factor for the effect of shear lag at ULS may be determined as for the elastic shear lag, with $\alpha_{0}$ replaced by $\alpha_{0}^{*}$ :

$$
\begin{gathered}
\alpha_{0}^{*}=\sqrt{\frac{A_{c \cdot e f f}}{b_{0} t}}=\sqrt{\frac{34.4 \cdot 2}{40 \cdot 2}}=0.927 ; \\
k=\frac{\alpha_{0}^{*} \cdot b_{0}}{L_{e}}=\frac{0.927 \cdot 40}{300}=0.124 ; \beta_{u l t}=\frac{1}{1+6.0 \cdot\left(k-\frac{1}{2500 \cdot k}\right)+1.6 \cdot k^{2}} ; b_{e f f}=\beta_{u l t} \cdot b_{0}=0.57 \cdot 400=228 \mathrm{~mm} ; \\
b_{\text {non-eff }}=800 \mathrm{~mm}-2 \cdot b_{\text {eff }}=344 \mathrm{~mm} .
\end{gathered}
$$

\section{Elastoplastic shear lag effects for limited plastic strains}

In this case, factors $\beta$ and $k$ are calculated as for the elastic shear lag, and shear lagplate buckling interaction is accounted by the reduction factor $\beta_{e-p}=\max \left(\beta^{k}, \beta\right)$ :

$$
\begin{gathered}
\beta_{e-p}=\max \left(\beta^{k}, \beta\right)=\max \left(0.553^{0.133} ; 0.553\right)=0.92 \\
b_{e f f}=\beta_{e-p} \cdot b_{0}=0.92 \cdot 400=368 \mathrm{~mm} \\
b_{\text {non-eff }}=800 \mathrm{~mm}-2 \cdot b_{e f f}=64 \mathrm{~mm}
\end{gathered}
$$

The effective and non-effective zones related to effective ${ }^{\mathrm{s}}$ widths determined as elastic shear lag, the combined effect of shear lag and plate buckling and shear lag effects with limited plastic strains are graphically presented in Fig. 6.
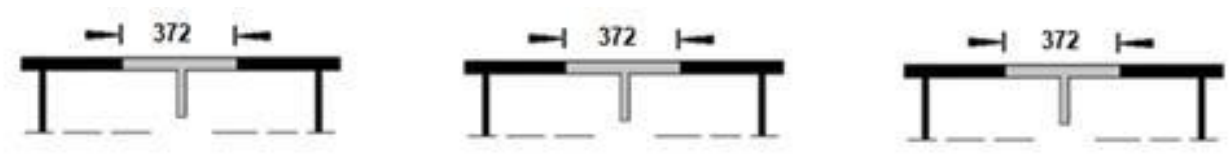

a)

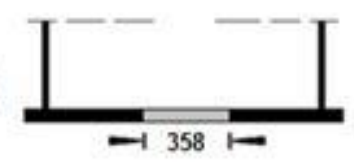

b)
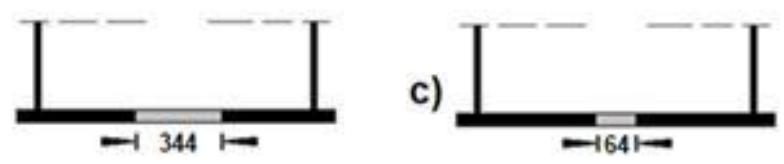

- effective zone

- non-effective zone

Fig. 6. Effective and non-effective zones of flanges at internal supports: a) elastic shear lag; b) combined effect of shear lag and plate buckling;

c) limited plastic strains 
It results that the elastic shear lag and the combined effect of shear lag and plate buckling give similar values for the effective length and the method based on limited plastic strains gives very different values (it is not so conservative).

In paper [5] and in handbook [3] some structures are analyzed from the shear lag point of view, respectively the evaluation of effectives width of the compression and of the tension flanges and the shear lag at the ultimate limit state.

\section{CONCLUSION AND FINAL REMARKS}

The term shear lag is related to some of the discrepancies between this approximate theory of the bending of beams and their real behaviour and refers to the increases of the bending stresses near the flange-to-web junctions, and the corresponding decreases in the flange stresses away from these junctions.

In relation to the effective width method, SR EN 1993-1-5. \$3.3 introduces three different designations for three types of effective width:

- effectives width - shear lag effects;

- effective ${ }^{\mathrm{p}}$ width - local buckling of plates;

- effective width - interaction of shear lag and local buckling of plates (method recommended in the norm EN1993-1-5).

According to EN 1993-1-5, the shear lag in the flanges may be neglected if $b_{0}<L_{e} / 50$.

When designing plated structures, the effects of shear lag, plate buckling and interaction of both effects should be taken into account at the ultimate, serviceability or fatigue limit states, because the shear lag and plate buckling reduce the stiffness of the plated structures.

The following observations should be noticed:

- the more stiffened the flange is, the smaller its effective ${ }^{\mathrm{s}}$ width results are;

- the flange width strongly influences the size of the effective ${ }^{\mathrm{s}}$ width;

- the girder span size has an important influence on the effective ${ }^{s}$ width of the flange, especially when the large flanges are combined with a small girder span (more specific a small effective length);

- when the shear lag at ultimate limit state is analyzed, one can make the observation that the elastic shear lag and the combined effect of shear lag and plate buckling give similar values for the effective length, while the method based on limited plastic strains gives very different values (it is not so conservative).

The working example presented in this paper is useful both in the design activity and to illustrate the determination of the shear lag effects according to EC1993-1-5.

\section{REFERENCES}

[1] Beg D., Kuhlmann U., Davaine L., Braun B. (2010), Design of Plated Structures. ECCS [2] Johansson B., Maquoi R., Sedlacek G., Müller C., Beg D. (2007), Commentary and worked examples to EN 1993-1-5 „Plated structural elements” (programme of CEN/TC 250)

[3] Moga P. (2018), Euronorme. Calculul elementelor metalice., Ed. U.T. PRESS, Cluj-Napoca [4] Trahair N.S., Bradford M.A., Nethercot D.A., Gardner L. (2008), The behaviour and design of steel structures to EC3. Taylor \& Francis. London. Fourth edition 
[5] Moga C., Feneşan Crina, Suciu M. (2020), Effective width of steel flange girders related to shear lag phenomenon, Buletinul Univ. Tehn. „Gh. Asachi”. Vol. 66. Nr. 1, pag. 71-83 [6] *** SR EN 1993-1-5: 2006. Eurocod 3 (EC3-1-5): Proiectarea structurilor de oţel. Partea 1-5: Elemente din plăci plane solicitate în planul lor

Note:

Raluca Nerișanu- Technical University of Cluj-Napoca, 28 Memorandumului Street, 400114-ClujNapoca, Romania (corresponding author to provide phone: +40-728-671024; e-mail: Raluca.Nerisanu@cfdp.utcluj.ro).

Cătălin Moga- Technical University of Cluj-Napoca, 28 Memorandumului Street, 400114-Cluj-Napoca, Romania (e-mail: Catalin.Moga@ dst.utcluj.ro).

Delia Drăgan- Technical University of Cluj-Napoca, 28 Memorandumului Street, 400114-Cluj-Napoca, Romania (e-mail: Delia.Dragan@cfdp.utcluj.ro). 